\title{
Economic Impacts on the United States of Siting Decisions for the International Thermonuclear Experimental Reactor: Executive Summary
}

by J.P. Peerenboom, M.E. Hanson, J.R. Huddleston, and T.D. Wolsko

Decision and Information Sciences Division,

Argonne National Laboratory, 9700 South Cass Avenue, Argonne, Illinois 60439

August 1996

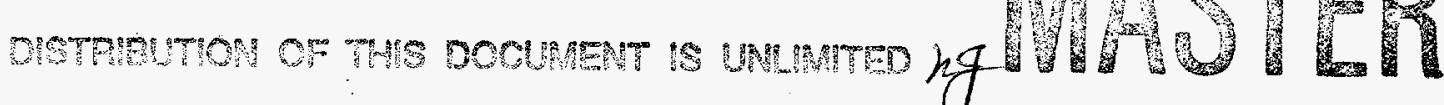
Work sponsored by United States Department of Energy, Office of Fusion Energy 
ary

This report is printed on recycled paper. 


\section{DISCLAIMER}

Portions of this document may be illegible in electronic image products. Images are produced from the best available original document. 
This study was conducted by a multidisciplinary team of economists and engineers from academia, the private sector, and the U.S. Department of Energy (DOE) national laboratory system. The study was managed by Argonne National Laboratory and supported by the DOE, Office of Fusion Energy. The team consisted of the following members:

\section{STUDY DIRECTORS}

\author{
Dr. Thomas D. Wolsko \\ Deputy Division Director \\ Decision and Information Sciences Division \\ Argonne National Laboratory
}

Dr. James P. Peerenboom

Group Leader, Systems Science

Decision and Information Sciences Division

Argonne National Laboratory

\section{NATIONAL ANALYSIS WORKING GROUP}

\author{
Dr. Gale A. Boyd \\ Economist \\ Argonne National Laboratory \\ Dr. Mark Hanson ${ }^{1,2}$ \\ Director of Technical Studies \\ Resource Management Associates \\ Dr. Douglas S. Meade \\ Economist \\ INFORUM, University of Maryland \\ Dr. Adam Z. Rose \\ Professor of Mineral Economics \\ Pennsylvania State University
}

Dr. Donald A. Hanson

Economist/Manager of Energy Policy Section

Argonne National Laboratory

Ms. Margaret B. McCarthy

Economist

INFORUM, University of Maryland

Dr. Ralph M. Monaco

Economist

INFORUM, University of Maryland

Mr. A. Michael Schaal ${ }^{3}$

Department of Mineral Economics

Pennsylvania State University

\section{LOCAL/REGIONAL ANALYSIS WORKING GROUP}

\begin{abstract}
Mr. Timothy Allison
Economic Geographer

Argonne National Laboratory

Dr. F. (Fredrick) Larry Leistritz

Professor of Agricultural Economics

North Dakota State University
\end{abstract}

\author{
Dr. Jack R. Huddleston ${ }^{1}$ \\ Professor of Urban and Regional Planning \\ University of Wisconsin-Madison \\ Dr. Stephen H. Pollock, Senior Manager ${ }^{4}$ \\ Barents Group, LLC of KPMG \\ Peat Marwick, LLP
}

1 Working Group leader.

2 Dr. Hanson is currently the Executive Director of the Energy Center of Wisconsin.

$3 \mathrm{Mr}$. Schaal is currently with Energy Ventures Analysis, Inc.

4 Dr. Pollock is currently with the Economic Consulting Services of KPMG Peat Marwick, LLP. 
The work described in this report was completed prior to the substantial restructuring of the fusion program's goals, objectives, and budget for fiscal year 1996 and beyond. Because of this restructuring, the U.S. government is no longer considering the possibility of hosting the International Thermonuclear Experimental Reactor (ITER). Nevertheless, continuing participation in the ITER Engineering Design Activities and the potential limited financial participation in future ITER construction and operation remain important parts of the new U.S. fusion energy sciences program. While some of the planning assumptions are no longer valid, this early 1995 strategy is being published with the hope that the methodology may be valuable to any further economic studies. 


\title{
Economic Impacts on the United States of Siting Decisions for the International Thermonuclear Experimental Reactor: Executive Summary
}

\author{
by \\ J.P. Peerenboom, M.E. Hanson, J.R. Huddleston, and T.D. Wolsko
}

\section{Introduction}

This summary highlights the results of a study that examined and compared the probable shortterm economic impacts of the International Thermonuclear Experimental Reactor (ITER) on the United States (U.S.) if (1) ITER were to be sited in the U.S. or (2) ITER were to be sited in one of the other countries that, along with the U.S., are currently participating in the ITER program. ${ }^{1}$ Life-cycle costs associated with ITER construction, operation, and decommissioning were analyzed to assess their economic impact. A number of possible U.S. "host" and U.S. "non-host" technology and cost-sharing arrangements were examined.

The study examined both national and local/regional economic impacts, as measured by gross domestic product (GDP), regional output, employment, income, and net exports. These impacts represent a portion of the complex, interrelated set of economic considerations that characterize U.S. host and U.S. non-host participation in ITER. Table 1 summarizes the findings of the study.

\section{Background}

As a potential future energy source, fusion - the process by which the sun and other stars produce energy - could produce large amounts of electricity for world use. Fusion is an attractive option because its fuel (isotopes of hydrogen) is virtually inexhaustible, and, unlike fossil fuels, it will not produce undesirable combustion products that damage air quality and contribute to global environmental problems. This promise

\section{Table 1 Summary of Study Findings}

- Hosting ITER (at an estimated life-cycle cost of about $\$ 8$ billion) would produce positive shortterm economic benefits in the United States (national level), as measured by changes in:

- Gross domestic product,

- Regional output,

- Employment,

- Income, and

- Net exports.

- Participating in ITER as a non-host Party (at an estimated life-cycle cost of about $\$ 3.9$ billion) would result in small negative economic consequences at the national level.

- Alternative cost-sharing arrangements among the host and non-host Parties could reduce or enhance the advantages of hosting versus non-hosting.

- The magnitude of economic impacts at the national level depends on the source of ITER funds within the U.S. economy.

- Hosting ITER would produce significant positive economic benefits in the area immediately surrounding the ITER site (local level).

- Local economic benefits could vary significantly as a result of site-specific characteristics.

has led the U.S. and other industrialized nations to actively engage in various fusion research and development (R\&D) programs - both collectively and separately — to harness its power.

\section{ITER Program}

One such program - the ITER program - was initiated in 1988 by the European Community 
(now known as the European Union), the Soviet Union (Russia is now honoring the former Soviet Union's commitment), Japan, and the U.S. (hereafter referred to as the "Parties"). This multiphase international $R \& D$ program ultimately aims to demonstrate the scientific and technological feasibility of magnetic fusion energy. To accomplish this goal, the ITER facility would demonstrate an extended and controlled fusion reaction, demonstrate technologies essential to a fusion reactor in an integrated system, and test the special components required for the practical use of fusion energy. This first-of-a-kind collaborative scientific project represents the next major milestone in the program: to develop magnetic fusion as an energy source. ${ }^{2}$

The Parties are currently conducting a six-year Engineering Design Activities (EDA) phase that will provide a foundation for deciding whether to construct and operate ITER either collaboratively or separately. However, no decisions have been made to commit to construction, and there is no agreed-upon decision-making schedule at this time. If a decision is made to construct ITER, one Party would probably serve as the host. The remaining Parties (non-hosts) would likely participate in constructing and operating the facility. Costsharing arrangements and the process by which the Parties will select a host country and ITER site remain open issues. ${ }^{3}$

\section{Study Approach and Scope}

The study used a two-phase approach to analyze the economic impacts of ITER (Figure 1). The first phase characterized ITER in terms of technological components and time-dependent expenditure data corresponding to specific ITER life-cycle activities and translated this information into a form suitable for the economic analysis models. Each ITER expenditure was assigned (or mapped) to a specific economic sector within the U.S. economy. Cost data were categorized as labor, equipment, and material. These data were based on pre-EDA ITER reports and the ITER Director's Outline Design Cost Estimate

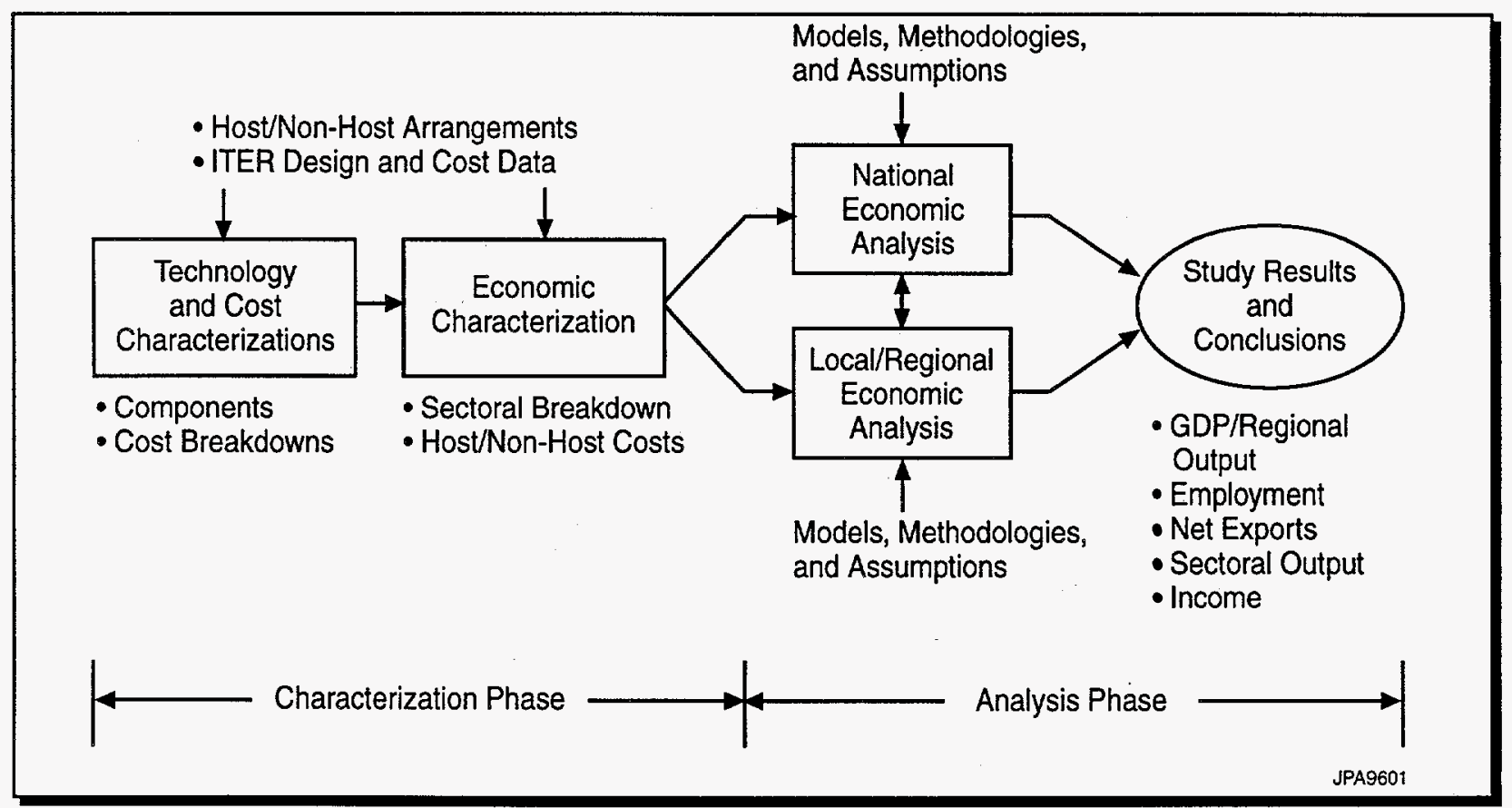

Figure 1 Phases of the Economic Study 
developed during the EDA. ${ }^{4,5}$ Assumptions about cost-sharing arrangements between the host and non-host Parties were used to determine financial responsibilities and where specific expenditures would occur.

The second phase analyzed the impact of ITER on the national economy and, if the U.S. were the host Party, on the local area that would serve as the site for the ITER project. Representative localities, rather than specific ITER sites, were used to estimate probable benefits. A methodologically consistent and robust set of analytic models was applied.

The study captures many of the direct and indirect economic impacts associated with ITER construction, operation, and decommissioning and provides insight into the expected magnitude of those impacts. However, a number of potential costs, benefits, and impacts associated with U.S. participation in the ITER program were not considered: the costs of the EDA; potential regulatory, licensing, and related costs; site selection, preparation, and local infrastructure costs (if the U.S. were the host Party); and spin-off and high-technology benefits. Further study would be required to estimate these potential costs and benefits.

In addition, the number of Parties involved in ITER construction, operation, and decommissioning could be either smaller or larger than the four Parties currently involved in the EDA and assumed in this study. Such a change would result in different levels of host/non-host cost sharing and alter the magnitude of economic impacts. Similarly, a number of different costsharing arrangements among the non-host Parties are possible, which would affect the magnitude of non-host economic impacts. Further study would obviously be needed in these cases to estimate the potential costs and benefits.

\section{ITER Cost Characterization}

Life-cycle ITER cost characterization data (in 1994 dollars) are summarized in Table 2. Construction ( $\$ 10$ billion), which is assumed to
Table 2 ITER Life-Cycle Costs (in billions of 1994 dollars)

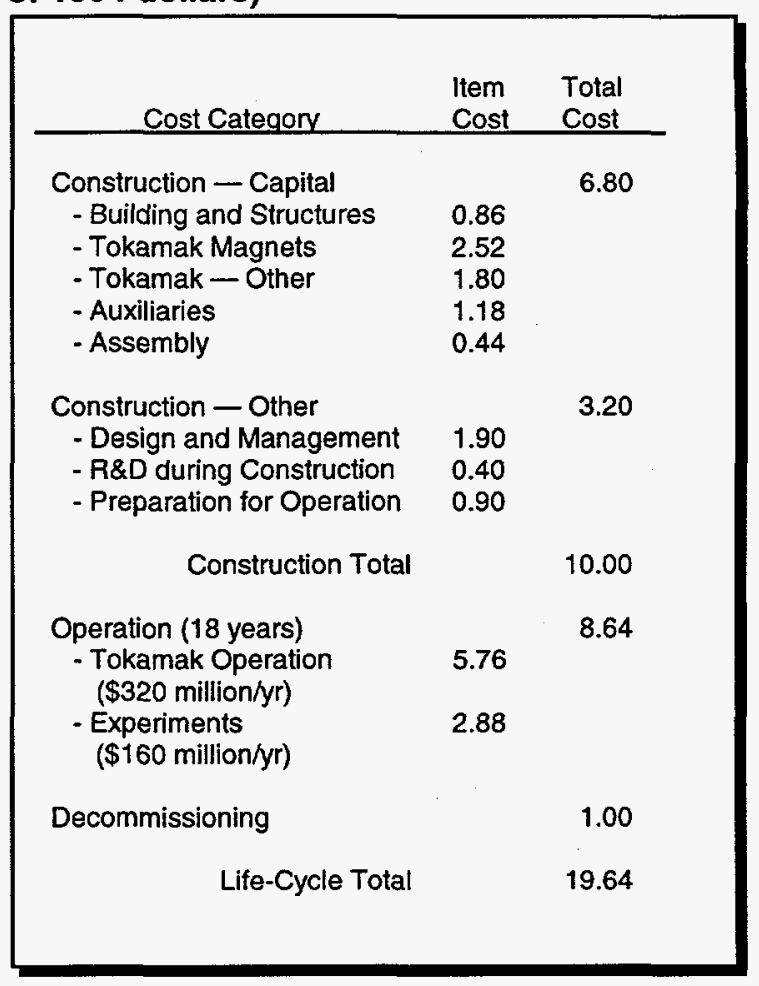

occur over an 8-year period starting in 1999 , is divided into capital cost items ( $\$ 6.8$ billion) and other construction support activities $(\$ 3.2$ billion). These categories account for $35 \%$ and $16 \%$ of the total life-cycle cost ( $\$ 19.64$ billion), respectively. Operation ( $\$ 8.64$ billion), which occurs over an 18-year period starting in 2007 , accounts for $44 \%$ of the total life-cycle cost. Decommissioning ( $\$ 1$ billion), which is assumed to occur over a 4-year period starting in 2025 , accounts for $5 \%$ of the total life-cycle cost.

Table 3 details host and non-host cost-sharing assumptions for the reference case. As no negotiations have begun, the identification of a reference case is purely a study assumption without benefit of interactions with the other ITER Parties. The Parties - a host and three non-hosts - were assumed to share ITER costs. For this study, the financial responsibility of each non-host Party was assumed to be identical; however, as mentioned earlier, other cost-sharing arrangements would be possible (e.g., unequal non-host shares). As Table 3 shows, the host is solely responsible for costs associated with 
Table 3 Host/Non-Host Cost-Sharing Assumptions (Reference Case)

\begin{tabular}{|c|c|c|c|}
\hline \multirow[b]{2}{*}{ Cost Category } & \multirow[b]{2}{*}{$\begin{array}{l}\text { Host Cost } \\
(\%)\end{array}$} & \multicolumn{2}{|c|}{$\begin{array}{l}\text { Non-Host Cost } \\
\text { Each Party (\%) }\end{array}$} \\
\hline & & $\begin{array}{l}\text { At Host } \\
\text { Site }\end{array}$ & $\begin{array}{c}\text { At } \\
\text { Home } \\
\end{array}$ \\
\hline \multicolumn{4}{|l|}{ Construction - Capital } \\
\hline $\begin{array}{l}\text { - Building and } \\
\text { Structures }\end{array}$ & 100 & 0 & 0 \\
\hline - Tokamak Magnets & 25 & 5 & 20 \\
\hline - Tokamak - Other & 25 & 0 & 25 \\
\hline - Auxiliaries & 25 & 0 & 25 \\
\hline - Assembly & 50 & 17 & 0 \\
\hline \multicolumn{4}{|l|}{ Construction - Other } \\
\hline $\begin{array}{l}\text { - Design and } \\
\text { Management }\end{array}$ & 25 & 10 & 15 \\
\hline $\begin{array}{l}\text { - R\&D during } \\
\text { Construction }\end{array}$ & 25 & 0 & 25 \\
\hline $\begin{array}{l}\text { - Preparation for } \\
\text { Operation }\end{array}$ & 40 & 10 & 10 \\
\hline \multicolumn{4}{|l|}{ Operation } \\
\hline $\begin{array}{l}\text { - Tokamak Operation } \\
\text { - Experiments }\end{array}$ & $\begin{array}{l}50 \\
25\end{array}$ & $\begin{array}{r}7 \\
10\end{array}$ & $\begin{array}{l}10 \\
15\end{array}$ \\
\hline Decommissioning & 100 & 0 & 0 \\
\hline
\end{tabular}

buildings and structures as well as with decommissioning. All Parties share equally in high-technology component costs and activities. Non-host costs are divided into two categories: costs incurred at home and costs incurred at the host site (Figure 2).

\section{National Analysis}

Objective and Scope. The national analysis estimated the relative economic changes that would affect the U.S. economy if the nation were to participate in the ITER project as either a host or non-host Party. The analysis was limited to short-term, direct and indirect economic impacts that would occur as a result of ITER expenditures during each year of the 30-year ITER life cycle. The potential long-term benefits of ITER and magnetic fusion energy (e.g., spinoff technology developments and increased energy security) were not addressed.

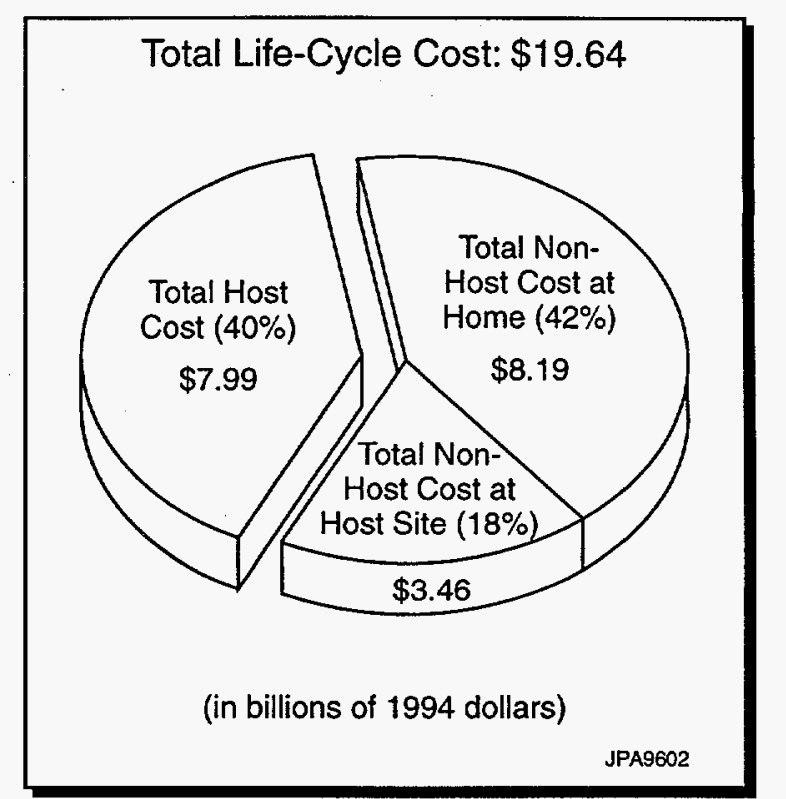
Figure 2 Distribution of Host/Non-Host
Life-Cycle Costs (Reference Case)

Methodology and Assumptions. The study assumed that ITER is funded within the U.S. federal budget in one of three ways: (1) realigning the discretionary federal nondefense budget (reference case), (2) realigning the federal nondefense science and technology budget, and (3) providing new (supplemental) budget expenditures. Two multisector models independently estimated and verified national ITER impacts. The analysis compared the national economy with and without ITER.

Results. Figure 3 compares the host and non-host budgetary requirements for ITER (reference case). Federal outlays over the entire project decrease from $\$ 7.99$ billion if the U.S. were the host to $\$ 3.88$ billion if the U.S. were a full-share non-host participant. Expenditures by non-host Parties at the host site (primarily for labor) would be approximately $\$ 2.08$ billion. Therefore, if the U.S. hosted ITER, total expenditures in the nation would be about $\$ 10.07$ billion. If the U.S. participated as a fullshare non-host, total expenditures in the nation 


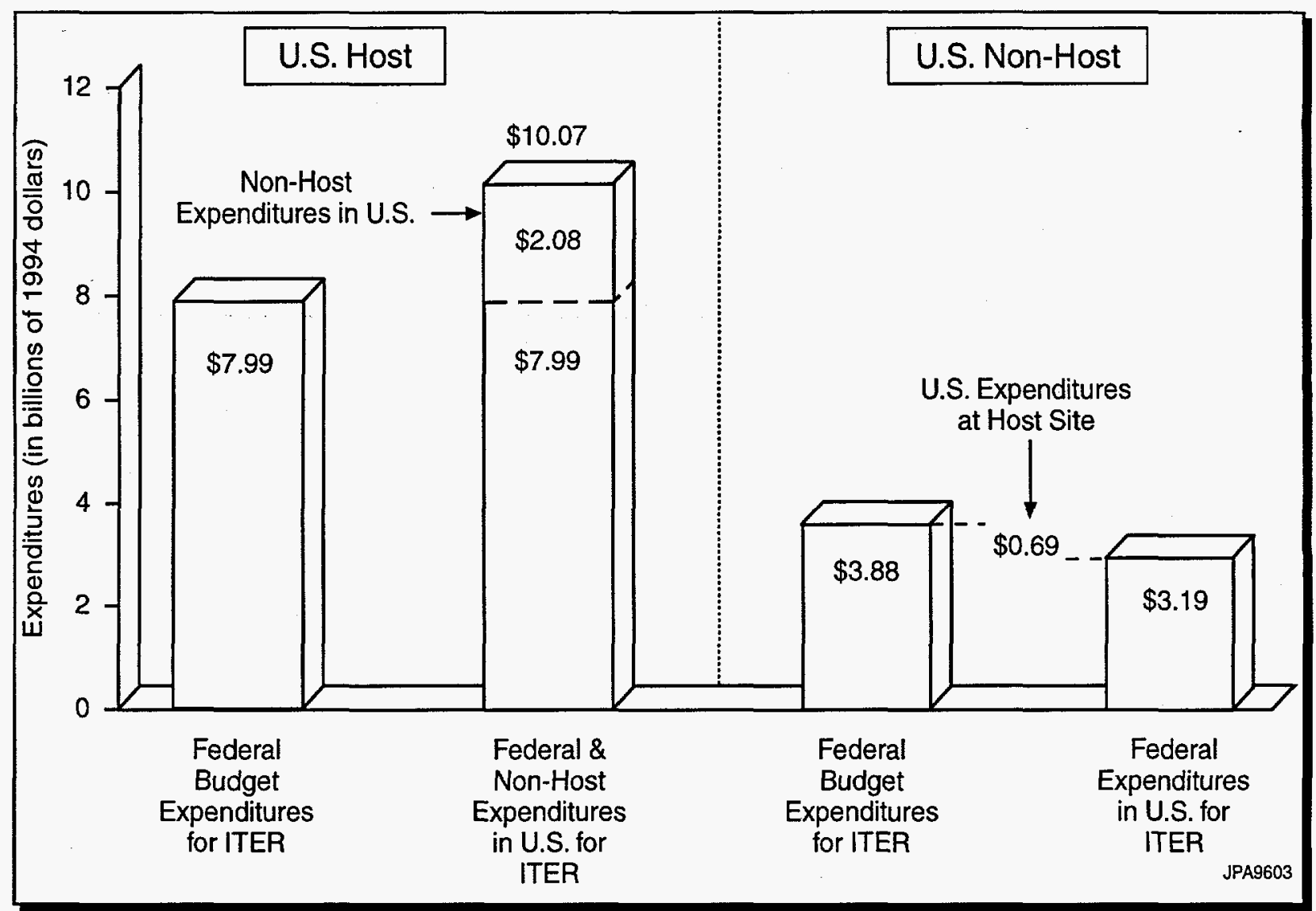

Figure 3 Comparison of U.S. Host vs. Non-Host Expenditures (Reference Case)

would be $\$ 3.19$ billion, although the total allocation from the federal budget would amount to $\$ 3.88$ billion. This cost increase occurs because U.S. scientists and engineers would spend money (estimated at $\$ 0.69$ billion) at a host site outside the U.S.

Hosting ITER would result in positive short-term economic benefits in the U.S., as measured by GDP. The source of funding for ITER is an important factor in determining the overall magnitude of such benefits. Gross domestic product could increase by as much as $\$ 1.2$ billion per year during construction if supplemental funds financed the U.S. portion of the project. For a realignment of existing nondefense federal programs, the short-term increase in GDP would fall to approximately $\$ 200$ million per year at its peak. While different in magnitude, neither of these estimated impacts on GDP is significant in the context of the $\$ 7$ trillion overall U.S. economy.
If the U.S. were a full-share non-host participant in ITER, the GDP would decrease by approximately $\$ 100$ million annually because of expenditures outside the U.S.

The impacts of ITER on national employment are minimal relative to the large national labor force (estimated in the analysis to be 136 million at the start of ITER construction). With supplemental funding for the U.S. share, national employment could increase by as many as 8,000 jobs at the peak of construction if the U.S. were the host. For a realignment of the federal nondefense budget, an increase of about 1,000 jobs would be expected. During the operation and decommissioning phases, the increase would be about 2,000 jobs under all conditions examined.

Net exports would generally increase under most conditions examined if the U.S. were the host. This increase occurs because expenditures by 
non-host workers in the U.S. (counted as exports) are greater than the increase in imports due to ITER. The maximum increase in net exports for a realignment of existing nondefense federal programs is $\$ 111$ million per year. Similarly, disposable income increases primarily because of increased GDP. With supplemental funding for the U.S. share, disposable income increases by $\$ 1.79$ per capita during peak construction.

If the U.S. were the host, federal tax revenues could increase by about $\$ 1$ billion over the 30-year project life. If the U.S. were a full-share non-host participant, a very slight dampening in the U.S. economy could be expected, as expenditures were "leaked" to the host country. In this case, federal tax revenues could decrease by about $\$ 600$ million over the 30 -year project life.

Non-host expenditures in the U.S. (if the U.S. were the host Party) are the primary reason for the positive short-term economic benefits under all conditions examined in the study, except when supplemental funds are assumed to be available. When such funds are available, they add to the short-term benefits of the non-host expenditures.

Depending on the exact cost-sharing arrangements among the host and non-host Parties, the economic stimulus in the host country as a result of visiting scientists could total several billion dollars over the life of the ITER project. Without this stimulus, the net effect of ITER on national employment, for example, would be slightly negative because the ITER expenditures for labor would go to fewer, more highly skilled workers (i.e., ITER workers would be expected to have higher skill and salary levels than those of the average U.S. worker).

Table 4 summarizes the estimates of the economic benefits of ITER on the national economy. The first number in the ranges of estimates corresponds to the case where ITER was funded from a realignment of the federal
Table 4 National Impacts

- Hosting ITER would result in small positive economic benefits at the national level as measured by:

- GDP ( $\$ 200$ million to $\$ 1.2$ billion in the peak year),

- Employment $(1,000$ to 8,000 jobs in the peak year),

- Net exports (\$111 million to $\$ 75$ million in the peak year), and

- Disposable income $(\$ 0.39$ to $\$ 1.79$ per capita in the peak year).

- The GDP, employment, and disposable income impacts in the peak year represent increases of approximately $0.01 \%$ over non-ITER levels.

- Net exports would increase by $0.5 \%$ in the peak year if the U.S. were host.

- Hosting ITER would increase federal revenues by about $\$ 1$ billion over the 30-year project life.

- If the U.S. were a full-share non-host participant, federal revenues would decrease by about $\$ 0.6$ billion over the 30 -year project life.

nondefense budget; the second number corresponds to the case where supplemental funds were assumed.

\section{Local/Regional Analysis}

Objective and Scope. The local/regional analysis estimated the probable economic benefits that would accrue to the local area that serves as the ITER site in the U.S. The analysis focused on the gross benefits (positive impacts) of the project, rather than on the net benefits. It measured economic variables, such as local output, personal income, and employment. Estimates were based on average impacts for a range of different size communities (specific ITER candidate sites were not examined). As a result, the analysis did not include the costs of providing additional infrastructure and public services to support ITER life-cycle activities and new residents. 
Methodology and Assumptions. The data and assumptions used to estimate local/regional impacts were consistent with those used in the national analysis. ITER labor, equipment, and material requirements were translated into purchases and sales by economic sector. As in the national analysis, a multisector model estimated the local benefits of ITER.

The total project expenditures at the ITER site will generally be smaller than at the national level because not all materials, equipment, and services will be available from local suppliers. This concept is illustrated in Figure 4, which compares direct ITER spending at the national and local levels (reference case). Over the ITER life cycle, spending at the local level is approximately $40 \%$ less than at the national level. The portion of direct purchases of materials and equipment and direct payments for labor that occur in the local area will stimulate the economy in that area.
Results. The local/regional area that serves as the ITER site in the U.S. will benefit substantially in terms of new employment, personal income, and output. While the benefits are likely to differ from the estimates presented here because of variations in local economies, the average benefits will probably be significant.

Direct employment at the ITER site (host and non-host workers) during construction, operation, and decommissioning would peak at approximately $4,400,1,400$, and 2,000 workers, respectively. Host workers would make up 52\% to $71 \%$ of all ITER workers during construction and $54 \%$ during operation. Host ITER workers would be solely responsible for decommissioning activities under the reference case.

The total benefits of ITER in a local/regional area would extend beyond direct employment at the ITER facility. Additional benefits would

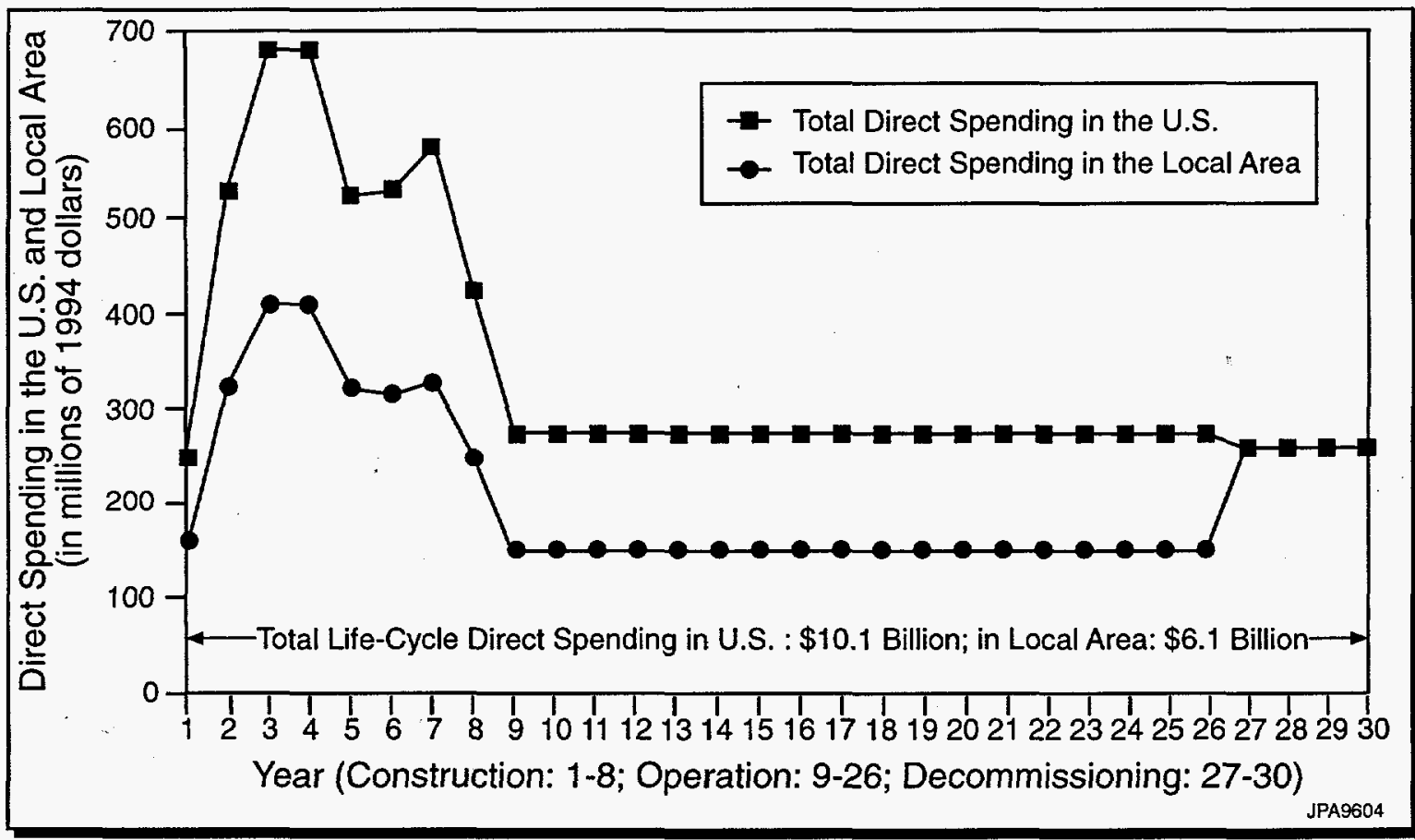

Figure 4 Direct Spending in the U.S. and Local Area (Reference Case) 
accrue from "secondary" or indirect employment in the local area. Table 5 summarizes the estimates of the economic benefits of ITER on the local economy that hosts ITER.

The production of firms and industries at the ITER site would also increase substantially because of direct sales to the ITER facility and purchases by ITER-related workers. The increase in local area total output would peak at about $\$ 690$ million per year during construction, increase by approximately $\$ 240$ million each year during operation, and climb to more than $\$ 450$ million per year during decommissioning. As shown in Table 5, new output would increase by more than $\$ 10$ billion over the life of the project.

Personal income at the host site would increase dramatically because of direct wages paid to ITER workers by both host and non-host countries and by the additional wages paid to indirect workers. Local area personal income would increase by more than $\$ 5$ billion over the life of the project, peaking at about $\$ 380$ million per year during construction.

A number of additional positive impacts are likely to occur in the location that hosts ITER that have not been measured in the analysis. These impacts include an expansion of the local tax base, improved infrastructure and public services, and increased industrial development (including new high-technology firms).

\section{Observations and Significant Issues}

The motivation for U.S. participation in ITER as either host or non-host Party - cannot be based on the short-term economic benefits derived from funds expended on the ITER project. Rather, the fundamental motivation for supporting ITER rests on future economic and environmental conditions; the potential for abundant commercial fusion energy; and the role ITER can play in moving toward the goal of safe, economical, and environmentally
Table 5 Local/Regional Impacts

- The local economy that hosts ITER would receive substantial benefits:

- More than 11,000 jobs would be created in the peak construction year, nearly 4,000 during operation, and almost 7,000 during decommissioning.

- ITER would create more than $\$ 5$ billion in additional personal income and more than $\$ 10$ billion in new output in the local economy during the life of the project.

- The absolute benefits of the ITER project would be less in an area with a smaller economy than in an area with a larger economy because a larger proportion of expenditures would likely be made outside the local area.

- The relative benefits of the ITER project would be smaller in large urban areas in comparison to small urban areas.

acceptable commercial fusion power. The shortterm economic benefits from participation in ITER - as described in this summary - are only part of the overall calculus that must be employed when considering the merits and direction of U.S. participation in the ITER program.

A comprehensive comparison of all the benefits of hosting or not hosting ITER could include such factors as the likelihood that service, supply, and spin-off companies might spring up near the ITER site. Other factors that could be considered are national prestige, the relative ease of supporting U.S. industry interest in fusion, the likelihood of technology transfer to

U.S. industry, and the relative impacts on the U.S. fusion scientific/engineering and hightechnology infrastructure.

If the U.S. were to host ITER, significant positive benefits would probably occur in some or all of the aforementioned areas. However, the magnitude of such potential benefits clearly depends on the cost- and technology-sharing arrangements among the host and non-host Parties. 
The U.S. would benefit to a similar degree as a non-host participant in ITER. For example, scientific/engineering information would be shared, and U.S. fusion-related industries would gain $R \& D$, construction, and operational experience.

Significant savings could also be gained through joint cooperation in the ITER program. Without such cooperation, the cost of construction, operation, and decommissioning would be approximately $\$ 20$ billion. Hosting ITER could reduce this life-cycle cost to a single Party to approximately $\$ 8$ billion (reference case), while preserving the overall level of expected benefits. While the short-term benefits to the national economy are minimal, local regions and future generations could realize significant benefits. A further reduction in life-cycle cost to about $\$ 4$ billion (reference case) is possible if the U.S. were one of three full-share non-host participants.

While a number of cost-sharing arrangements are possible, including varying the number of ITER Parties and their contributions, the general trends of small positive impacts at the national level and substantial positive impacts at the local/regional level would be expected if the U.S. were host. Similarly, if the U.S. were one of the non-host Parties, the same general national economic trends of small negative impacts would apply.

\section{References}

1. J.P. Peerenboom, M.E. Hanson, J.R. Huddleston, T.D. Wolsko, S.H. Pollock, D.S. Meade, T. Allison, D.A. Hanson, A.Z. Rose, A.M. Schaal, and R. Monaco, Economic Impacts on the United States of Siting Decisions for the International Thermonuclear Experimental Reactor, ANL/DIS-2, Argonne National Laboratory, Argonne, Ill. (Aug. 1996).

2. International Thermonuclear Experimental Reactor, DOE/ER-ITER-0004, U.S. Department of Energy, Washington, D.C. (1993).

3. Interim Report to the Congress on Planning for International Thermonuclear Experimental Reactor Siting and Construction Decisions, U.S. Department of Energy, Washington, D.C. (Nov. 21, 1994).

\section{Preliminary ITER Cost and Schedule} Estimates, ITER Documentation Series No. 14, International Atomic Energy Agency, Vienna, Austria (Aug. 1990).

5. Detail of the ITER Outline Design Report, Vols. I-III, prepared for the 4th Meeting of the ITER Technical Advisory Committee, San Diego Joint Work Site, San Diego, Calif. (Jan. 10-12, 1994).

For additional information, contact:

Dr. James P. Peerenboom

Group Leader, Systems Science

Decision and Information Sciences Division

Argonne National Laboratory, Bldg. 900

9700 South Cass Avenue

Argonne, Illinois 60439

Phone: 630-252-8994

Fax: 630-252-6073

E-mail: jpeerenboom@anl.gov 


\section{DISTRIBUTION FOR ANLIDIS-2-ES}

\section{Internal}

ANL Technical Publications Services

J. Peerenboom (288)

L. Welko (5)

M. Clemmons

\section{External}

U.S. Department of Energy Office of Scientific and Technical Information (12)

Manager, U.S. Department of Energy Chicago Field Office

ANL-E Libraries

ANL-W Libraries 